\title{
Dinamika Gerakan Pembebasan Muslim Moro di Filipina Selatan: Studi Terhadap Moro National Liberation Front (1971-1996)
}

\author{
Firmanzah \\ Fakultas Adab dan Humaniora \\ Universitas Islam Negeri Raden Fatah Palembang, Indonesia \\ E-mail: firmanzah_uin@radenfatah.ac.id
}

\begin{abstract}
Abstrak
Muslim Filipina harus berjuang dari penindasan pemerintah Filipina dan melawan kelompok-kelompok Kristen yang lebih diakui pemerintah Filipina. Beberapa tahun setelah kemerdekaan Republik Filipina, masyarakat Muslim Moro menjalani hidup penuh kemiskinan, penuh diskriminasi dan tidak diperhatikan pemerintah Filipina. Gerakan pembebasan Moro National Liberation Front, diketahui bahwa lahirnya Moro National Liberation Front setelah peristiwa yang tidak berperikemanusiaan yaitu Tragedi Jabidah atau Jabidah Masarce di mana pembantaian pemuda muslim di pulau Corregidor karena menolak operasi merdeka mengambil Sabah dari wilayah territorial Malasyia. Muslim Moro di Filipina Selatan merasakan pemerintah Filipina yang berpusat di Manila melakukan penindasan dan kezaliman kepada mereka. Karena tujuan pemerintah bertujuan untuk pemerataan tanah Muslim di Filipina Selatan demi kepentingan ekonomi dan politik. MNLF mempunyai strategi dan kegiatan yang diperjuangkan MNLF sebagai bentuk pembebasan umat Islam dari segala hegemoni dan segala kolonialisme baik secara fisik maupun penyadaran umat Islam untuk kembali memperjuangkan hak-hak Muslim Moro.
\end{abstract}

Kata Kunci: Dinamika, Gerakan, Moro, Filipina Selatan

Minoritas Muslim adalah sebagian masyarakat yang menganut agama Islam dalam suatu negara. Mereka disebut minoritas karena kalah jauh dalam hal jumlah dengan masyarakat mayoritas. Mereka sering mendapat perlakuan berbeda dari masyarakat yang tidak berkeyakinan Muslim. Mereka harus menentukan nasibnya sendiri sekalipun menjalin kerjasama dengan berbagai pihak. Masyarakat minoritas harus bersedia memperjuangkan kepentingannya (Sukandia, 1999: 180. Faktor-faktor yang membuat suatu komunitas menjadi minoritas adalah perbedaan etnis warna kulit, ras, agama dan sebagainya.

Menurut Azyumardi Azra dalam pengantarnya di buku M. Ali Kettani yang berjudul Minoritas Muslim di Dunia Dewasa ini: "Dia mengatakan bahwa jika kelompok mayoritas adanya ciri-ciri yang berbeda dan mulai memberikan perlakuan yang berbeda kepada sekelompok orang yang dianggap berbeda, maka tindakan kelompok mayoritas akan membangkitkan kesadaran orang yang dianggap dengan ciriciri berbeda. Tindakan diatas mempersulit sebuah kelompok etnis minoritas dalam suatu Negara untuk berintegrasi jika berbagai identitas menumpuk menjadi satu. Umat Muslim masih berharap mendapat otonomi sendiri atau paling tidak menjadi penguasa atas masyarakat mereka (Kettani, 2005: 1)." 


\section{Firmanzah}

Dinamika Gerakan Pembebasan Muslim Moro di Filipina Selatan:

Studi Terhadap Moro National Liberation Front (1971-1996)

Adapun Minoritas Muslim di Asia Tenggara adalah Muslim Rohingnya yang tidak mendapat pengakuan dari pemerintah Myanmar yang mayoritas penganut agama Budha, Muslim Pattani yang mendapat kekerasan dari mayoritas agama di Thailand, dan Muslim Moro yang mendapat perlakuan kurang menyenangkan dari mayoritas agama di Filipina.

Muslim Filipina adalah komunitas Islam yang mayoritas. Islam menjadi minoritas di Filipina setelah terjadi kolonialisme tahun 1521-1946 dari negara-negara barat seperti Spanyol dan Amerika Serikat. Islam di Filipina menjadi minoritas juga dikarenakan adanya imigran non-Muslim dari Filipina Utara ke Filipina Selatan. Islam berkembang di Filipina melalui pedagang-pedagang Muslim Arab pada abad $10 \mathrm{M}$ sebelum agama Katolik yang dibawa oleh Spanyol menyebar di Filipina. Islam berkembang pertama kali di wilayah Filipina bagian Selatan yaitu di Kepulauan Sulu dan Mindanao. Pedagang Muslim Arab sampai di Filipina saat mereka mulai melakukan aksi perdagangan di Pulau Borneo (Yahya, 1993: 573-574).

Caesar Adib Majul di dalam bukunya Dinamika Islam Filipina mengatakan: "Setelah para pedagang mengenal Pulau Borneo, para pedagang bergegas menuju Filipina Selatan sebelum melanjutkan perjalanan menuju Cina. Kapal-kapal pedagang Arab kembali singgah di Kota Mindoro setelah berlayar dari Cina pada tahun $958 \mathrm{M}$. Hal ini menjelaskan bahwa Islam telah diperkenalkan di Filipina kira-kira ke-10. Islam di Filipina pada abad 10-15 adalah masyarakat mayoritas, tetapi sejak abad ke-15 dan selanjutnya, status masyarakat Muslim Moro menjadi minoritas (Majul, 1989: 3).”

Permasalahan Muslim Filipina diawali pada masa kolonial Spanyol, dilanjutkan Amerika Serikat, masa peralihan, pasca kemerdekaan hingga saat ini telah berkembang pemberontak dari kelompok Abu Sayyaf. Muslim Filipina harus berjuang dari penindasan pemerintah Filipina dan melawan kelompok-kelompok Kristen yang lebih diakui pemerintah Filipina. Beberapa tahun setelah kemerdekaan Republik Filipina, masyarakat Muslim Moro menjalani hidup penuh kemiskinan, penuh diskriminasi dan tidak diperhatikan pemerintah Filipina.

Proses Islamisasi berhenti sejak kedatangan kolonial Spanyol. Hal ini menyebabkan Islam tidak memiliki kesempatan untuk berkembang secara penuh di wilayah Filipina. Sejak masuknya Spanyol ke Filipina pada 16 Maret 1521, penduduk pribumi mencium adanya maksud lain dibalik ekspedisi ilmiah pemimpin mereka, Ferdinand de Magelland. Spanyol menaklukan wilayah Utara Filipina dengan mudah dan tanpa perlawanan. Akan tetapi, tidak demikian dengan wilayah Selatan Filipina. Tentara Spanyol bertempur untuk menguasai Pulau Mindanao dan Sulu.

Kesulitan menaklukan Selatan Filipina membuat Koloni Spanyol memusuhi masyarakat Muslim setempat dan menjajah Filipina selama tiga ratus tahun. Spanyol menganggap Pulau Mindanao dan Sulu merupakan bagian dari teritorialnya meskipun Spanyol gagal menaklukan kedua wilayah tersebut. Spanyol menyadari bahwa 
penduduk wilayah Selatan melakukan perlawanan yang gigih, berani dan pantang menyerah. Hal tersebut membuat Koloni Spanyol untuk menyerah dalam menaklukan wilayah Filipina Selatan, maka dari itu Spanyol menjual Filipina kepada Amerika Serikat seharga US\$ 20 juta pada tahun 1898. Kekuasaan Spanyol atas Filipina beralih kekuasaan ke Amerika Serikat. Amerika datang untuk menjunjung tinggi hak dan kebebasan warga negara dalam memilih agama dan beribadah sesuai dengan kepercayaannya (Apipudin, 2008: 109).

Amerika juga menampilkan diri sebagai sahabat baik dan dapat dipercaya ketika datang ke Mindanao untuk pertama kali. Amerika membebaskan kehidupan beragama, karena agama bukan tujuan Amerika. Tujuan kebijakan kolonial Amerika adalah untuk membaratkan masyarakat Muslim agar mampu memerintah dirinya sendiri sejajar dengan masyarakat non-Muslim. Kebijakan Amerika Serikat di Mindanao dan Sulu bergeser kepada sikap campur tangan langsung dan penjajahan, setahun kemudian Mindanao dan Sulu disatukan menjadi wilayah propinsi Moroland dengan alasan untuk memberadakan masyarakat Mindanao dan Sulu. Amerika memiliki hak legislatif pada masa itu. Amerika membuat peraturan agar rakyat Filipina Utara bermigrasi ke Selatan demi kehidupan yang lebih layak.

Masyarakat non-Muslim di bagian Filipina Utara berbondong-bondong menguasai tanah di kawasan Moro karena secara hukum Filipina dibolehkan. Peringatan migrasi masyarakat dari Utara ke Selatan terjadi sekitar tahun 1950-1960. Masyarakat Muslim Moro sangat prihatin dengan kondisi ini karena mereka menjadi minoritas di wilayah sendiri. Masyarakat Muslim Moro merasa bahwa pemerintah telah membantu masyarakat Kristen memindahkan hak atas tanah Moro dan membatasi ruang gerak masyarakat Moro sebagai Muslim. Oleh karena itu masyarakat Muslim Moro segan untuk berinteraksi dengan Filipina.

Kemerdekaan yang didapatkan Filipina pada tahun 1946 dari Amerika tidak memiliki arti khusus bagi masyarakat Moro. Setelah penjajahan Amerika dari Filipina, ternyata memunculkan penjajah baru (pemerintah Filipina). Masyarakat Moro sering mendapat tekanan pada masa kepemimpinan Presiden Ferdinand Marcos (1965-1986). Masa pemerintahan Ferdinand Marcos merupakan masa pemerintahan paling represif (mengekang) bagi masyarakat Muslim Moro. Perhatian Marcos dipusatkan kepada pemusnahan Muslim Filipina. Dalam menjalankan agendanya ini, Marcos dibantu kaum Yahudi dan negara-negara Kristen, terutama Amerika Serikat. Marcos juga mengumpulkan sejumlah kelompok untuk meneror kaum Muslim, merampas tanahtanah mereka, dan mengusir mereka dari negeri, mereka ditugaskan membuat rusuh wilayah-wilayah Muslim di Filipina. Berbagai kejahatan pun mereka lakukan, seperti pembunuhan, penghancuran, dan pengusiran (Ibrahim, 2014: 1071-1072).

Agenda kedua Marcos juga dijalankan, yaitu memberi orang-orang KristenFilipina tempat tinggal di tanah-tanah milik kaum Muslim. Kelompok-kelompok ciptaan Marcos mulai beraksi pada 1970 M, dibantu pemerintah berkuasa Filipina. 


\section{Firmanzah}

Dinamika Gerakan Pembebasan Muslim Moro di Filipina Selatan:

Studi Terhadap Moro National Liberation Front (1971-1996)

Kaum Muslim mencoba melancarkan protes, tapi sama sekali tidak di gubris pemerintah. Mereka tidak mempunyai cara lain untuk mempertahankan wilayah kecuali dengan media Jihad. Jihad bukan berati pengislaman yang dipaksakan. Jihad adalah upaya sepenuh tenaga dari kaum muslimin untuk meningkatan kebajikan dalam diri mereka sendiri dan dalam lingkungan sosial mereka, ini berarti satu-satunya jalan yaitu berperang untuk melindungi kemerdekaan kaum muslimin, yaitu meningkatkan hal tersebut untuk melawan agresi (Esposito, 1987: 300).

Pada Tahun 1968 terjadi peristiwa yang sangat tidak beperikemanusian bagi Muslim di Filipina Selatan yaitu generasi muda Muslim di latih, setelah dilatih mereka dibunuh secara biadab di pulau Corregidor, peristiwa ini lebih dikenal dengan Tragedi Jabidah. Tragedi Jabidah telah mengorbankan masyarakat Muslim Moro di Corregidor dan mendorong tokoh politik Islam Filipina bernama Nur Misuari untuk bangkit memperjuangkan nasib Muslim Moro melalui organisasi. Nur Misuari adalah pencetus berdirinya organisasi Moro National Liberation Front (MNLF) tahun 1971. Kesadaran Nur Misuari tentang tindakan sewenang-sewenang pemerintah muncul ketika beliau menjadi tokoh dalam demonstrasi-demonstrasi menentang tragedi Jabidah di pulau Corregidor (Chaidar, 1999: 39).

Peristiwa yang melibatkan masyarakat Muslim Moro etnis Tausug dan Samal ini telah menggoyah pemikiran Nur Misuari sebagai keturunan masyarakat Tausug untuk terus berjuang melawan tindakan sewenang-wenang pemerintah atas umat Islam. Nur Misuari ikut berperan dalam aksi di Istana Malacanang bersama mahasiswa Muslim Moro di Manila. Para demonstran mengeluarkan aksi protes dan memutuskan bahwa satu-satunya alternatif untuk merdeka dari Manila dan menciptakan masyarakat Moro yang independen adalah mendirikan sebuah persatuan kemerdekaan Islam. Nur Misuari, Profesor di Universitas Filipina, dia sadar dan bangkit untuk menjadi pemimpin organisasi MNLF pada tahun 1971. MNLF adalah gerakan pembebasan Muslim Filipina dan motif dari gerakan ini adalah melakukan aksi radikal dengan harapan dapat mencapai kemerdekaan, atau setidaknya mendapat otonomi daerah untuk Filipina Selatan. Tetapi yang paling penting adalah bahwa MNLF telah mendemonstrasikan dirinya menjadi kelompok bersenjata Islam yang secara militer diorganisasi dengan baik dan kuat.

\section{Latar Belakang Lahirnya Gerakan Pembebasan Moro National Liberation Front}

Tekanan yang didapatkan Muslim Moro oleh pemerintah Filipina semakin terasa hebat dan berat ketika Ferdinand Marcos berkuasa (1965-1986). Dibandingkan dengan masa pemerintahan semua presiden Filipina, dari Jose Rizal sampai Fidel Ramos merupakan masa pemerintahan paling represif bagi bangsa Moro (Hidayat, 2000: 7576). Nasib umat Islam tidak juga bertambah baik (Saifullah, 2010: 132). Rezim Marcos yang berkuasa cenderung menerapkan kebijakan represif kepada setiap bentuk perlawanan masyarakat Mindanao kepada pemerintah, baik yang dilakukan oleh kelompok Mindanao Muslim ataupun kelompok komunis (Surwandono, 2013: 71). 
Semasa pemerintahan Marcos, Istana Malcanang banyak berubah, Manila juga berubah (Seagrave, 1996: 2). Periode paling krusial konflik antara pemerintah Filipina dengan masyarakat Mindanao adalah pada masa presiden Marcos. Perhatian Marcos dipusatkan kepada pemusnahan Muslim Filipina. Dalam menjalankan agendanya, Marcos dibantu kaum Yahudi dan negara-negara Kristen, terutama Amerika Serikat. Marcos juga mengumpulkan gangster untuk meneror kaum Muslim, merampas tanah-tanah mereka, dan mengusir mereka dari negeri. Mereka ditugaskan membuat rusuh wilayah-wilayah Muslim di Filipina (Ibrahim, 2014: 1071).

Selama masa pemerintahan Ferdinand Marcos, persoalan Muslim Moro diselesaikan dengan setengah hati (Alchaidar, 1999: 37). Beragam penyiksaan, pembunuhan, ataupun mengirim pasukan sipil. Dalam hal ini etnis Ilaga untuk membantai masyarakat Mindanao cenderung menjadi kebijakan pokok dengan diberlakuannya Martial Law (Suwandono, 2013: 3). Hal ini terbukti dengan terjadinya "Peristiwa Jabidah" (Jabidah Massacre) di awal tahun 1968. Dalam peristiwa tersebut generasi muda Muslim dilatih secara rahasia oleh militer untuk kemudian dibunuh secara biadab di sebuah pulau di teluk manila. Sekitar 28 pemuda calon anggota militer yang semuanya Muslim Moro di bawah unit seorang Komando Militer yang notabene seorang Katolik pada maret 1968. Namun tidak diduga ternyata alasan mereka menolak ditugaskan untuk operasi adalah kesamaan agama (sesame Muslim) dan etnis (Melayu) serta kedekatannya dalam relasi keseharian masyarakat Sabah dan Malasyia. Karena penolakan itulah, calon tentara yang Muslim itu dibantai secara bersamaan (Sauedy, 2012: 53).

Pemerintah Marcos menganggap penolakan ini sebagai bentuk perlawanan masyarakat Mindanao terhadap kekuasaan pemerintah kekuasaan. Peristiwa itu kemudian dikenal pembantaian Jabidah (jabidah genoside). Pada waktu yang sama, muncul pasukan para-militer Kristen yang disebut Ilaga, yang telah dilatih secara kemiliteran, diketuai oleh Kolonel Carlos Cajela dan Kapten Manual Tranco. Organisasi rasialis Ilaga ini ditugaskan untuk menghancurkan umat Islam, dengan merampok harta benda dan membunuh Muslim.

Pada juni 1971, sejumlah 200 orang umat Islam telah dibunuh oleh Ilaga. Menurut pengakuan Ilaga sendiri, mereka telah berhasil membunuh 50.000 orang umat Islam, membakar lebih dari 500 masjid, 200 madrasah, 20.000 buah rumah. Keganasan Ilaga yang mirip dengan KKK Amerika ini membuat masalah ini diangkat ke tingkat internasional. Menurut catatan, pada September 1971, terjadi pembunuhan 111 orang di Bual, Tulunan, dan Cotabato. Pada 22 september 1971, 36 orang terbunuh di Tacub, Kauswaga, dan Lanodel Norte. Semenjak peristiwa pertama pada maret 1968 hingga 1972 diperkirakan 95.000 orang telah terbunuh, 300.000 orang kehilangan tempat tinggal, dan ladang pertanian yang sangat luas dimusnahkan.

Pada 1 Mei 1968 suatu perubahan yang radikal terjadi dalam hubungan antara umat Katholik dan umat Islam di Mindanao. Bekas Gubernur Cotabato, Datu Utdoh 


\section{Firmanzah}

Dinamika Gerakan Pembebasan Muslim Moro di Filipina Selatan:

Studi Terhadap Moro National Liberation Front (1971-1996)

Matalam, mengumumkan berdirinya Muslim Independence Movement/MIM (Gerakan Kemerdekaan Islam) yang bertujuan memperjuangkan kemerdekaan bagi Mindanao dan Sulu (Alchaidar, 1999: 38). Barangkali kita dapat memastikan bahwa awal dari gerakan Muslim Moro pada masa kemerdekaan berawal dari gerakan MIM, yang akan menjadi cikal bakal lahirnya suatu pergerakan yang akan menjadi simpati negara-negara Islam dan internasional (seperti MNLF, MILF, dan Abu Sayyaf Group).

Caesar Adib Majul dalam karyanya terakhir, The Contemporary Moslem Movement in the Philippines yang dikutip dari bukunya Saiful Muzani, Pembangunan Dan Kebangkitan Islam Di Asia Tenggara mengatakan bahwa: "Gerakan yang dilakukan Muslim Moro sedikitnya mempunyai tiga karakter: kesadaran yang meningkat terhadap Islam suatu kebangkitan di kalangan Muslim; komitmen mereka untuk membentuk kembali stuktur sosial, politik, dan kebudayaan dari komunitas mereka untuk mewujudkan cita-cita Islam secara lebih baik; dan usaha mereka yang penuh semangat untuk menghilangkan kekuatan dari luar maupun dalam yang menganggu atau mengancam masyarakat mereka yang berpegang pada cita-cita ideal Islam" (Muzani, 1993: 311).

MIM yang berati Gerakan Kemerdekaan Islam yang muncul di bagian Selatan Filipina, Datu Utdoh Matalam selaku pendiri MIM juga menandatangani suatu manifesto di daerah Pagalungan, Prov. Cotabato, yang menyerukan agar seluruh daerah yang penduduknya mayoritas beragama Islam di bagian Selatan bersatu dibawah sebuah negara yang dinamakan Republik Mindanao dan Sulu. Manifesto tahun 1968 tersebut merupakan awal dari suatu gerakan yang lebih teratur, lebih terorganisir untuk memisahkan diri dari pemerintah Filipina. Tanggapan terhadap manifesto itu ialah terbentuknya "Muslim Independen Movement" yang kemudian berubah menjadi Independent Muslim Movement. Kemudian karena dianggap istilah tertentu tidak tetap, maka berubahlah menjadi "Mindanao Independent Movement (atau) atau MIM.

Gerakan MIM masih merupakan gerakan untuk mengumpulkan masa dan simpati dari umat Islam, sampai mencari pemimpin yang akan dijadikan panutan oleh para anggotanya. Gerakan ini menuntut didirikannya sebuah Republik Islam di Mindanao dan Sulu. Bersamaan dengan itu, suatu kelompok bersenjata yang dinamakan Tentara Bangsa Moro dibentuk di Sulu pada 1968 atau 1969 yang kemudian menjadi tentara gerilya yang sangat tergorganisasi dan sangat terlatih (Kuntowijoyo, 1991: 73). Sementara itu kondisi dan keamanan di Filipina justru mendorong pematangan gerakan kearah yang lebih radikal dan lebih keras. Salah satu diantaranya adalah kasus pembantaian di pulau Corregidor.

Terkait dengan pendapat yang dikatakan Kamarulzaman Askandar diatas, setidaknya memberikan dalam memahami akar masalah Muslim Moro di Mindanao yang awal lahirnya sebuah pergerakan berawal dari tragedi Jabidah. Respon terhadap tragedi Jabidah dan pemberlakuan Martial Law yang semakin memarginalkan masyarakat Mindanao pada awalnya cenderung disikapi oleh para elite tua (Sultan di 
Mindanao) dengan cara-cara kultural dan ekonomi. Dalam pandangan para Sultan Mindanao peristiwa ini tidak lepas dari persoalan miskomunikasi ataupun salah pengertian akibat perbedaan budaya.

Tragedi Jabidah sangat berpengaruh bagi masyarakat Muslim Moro di Selatan. Peristiwa ini telah memancing terjadinya pemberontakan yang dilakukan pasukan militer Kristen kepada penduduk Muslim di Selatan Filipina. Berpusat pada gerakan baru masyarakat Muslim Moro, yaitu Front Pembebasan Nasional Moro (MNLF), pemberontakan dipimpin oleh generasi baru terdidik dari Universitas Muslim di Selatan yang dikonseptualisasikan oleh masyarakat Moro, bukan sebagai Tausug atau Samal dari Sulu; Maguindanao dari Cotabato (Mindanao); Maranao atau Iranun dari Lanao (Mindanao); Palawani atau Molbog dari Palawan. Semua bukan karena kesetiaan para Sultan, tetapi sebagai masyarakat Muslim Moro yang terpisah dari bagian lain Filipina.

Nur Misuari sebagai ketua MNLF menganggap bahwa konflik Mindanao sebagai konflik yang bersifat rasial karena telah terjadi politik genosida terhadap komunitas Muslim. Konflik Mindanao telah menempatkan etnis Islam menjadi korban utama dari kebijakan pemerintah Filipina, sehingga Misuari mengajak kepada komunitas Islam internasional untuk meperhatikan masalah ini secara serius. Misuari juga meminta kepada seluruh datus di Mindanao untuk bersatu padu untuk mendesak pemerintah Filipina untuk menghentikan genosida, diskriminasi, marginalisasi masyarakat Muslim di Mindanao dengan mengeluarkan Manifesto Moro yang kemudian menjadi embrio lahirnya organisasi pembebasan Moro (Moro National Liberation Front).

Munculnya kelas terpelajar dan terdidik Muslim Mindanao sebagai buah dari kebijakan pemerintah dengan politik etis pasca kemerdekaan menjadi barisan para elit baru yang lahir sebagai pemimpin yang terdidik dan modern. Mereka umumnya mengandalkan kemampuan dan ilmu pengetahuan dari pada warisan kepemimpinan dari stuktur sosial lama yang feodal atau datu. Nur Misuari, atau Nurallaj Misuari merupakan pengagas, pelopor dan pemimpin MNLF, adalah anak dari keluarga miskin berasal dari suku Tausug di jolo yang mendapatkan beasiswa dari program politik etis pemerintah tersebut yang kemudian hari menjadi professor studi Islam di University of the Philippines. Sedangkan Salamat Hasyim adalah kelahiran Cotabato dari suku Maguindanao yang kemudian menjadi pendiri dan pemimpin MILF yang juga anak keluarga biasa yang mendapat beasiswa dari pemerintah Mesir untuk melanjutkan kuliah di Universitass Al-Azhar, Kairo (Sauedy, 2012: 147-148).

Pada bulan April 1974, sebuah interview dengan Komandan Bangsa Moro Army (MNLF) berinisial "Ulang Utan" semakin memperjelas mengapa Bangsa Moro membentuk MNLF: pertama, karena kejadian Pembantaian Corregidor; kedua, karena penyerobotan tanah; ketiga, karena kekcewaan yang meluas di kalangan massa terhadap kegagalan pemerintah untuk mengatasi banyak problem sosial, politik, dan ekonomi. Insiden Corregidor sangat berpengaruh dan karenanya kepemimpinan MNLF akhirnya 


\section{Firmanzah}

Dinamika Gerakan Pembebasan Muslim Moro di Filipina Selatan:

Studi Terhadap Moro National Liberation Front (1971-1996)

menjalin ikatan dengan Malasyia. Pada tahun 1969 pemerintah Malasyia memberikan pelatihan militer dan keorganisasian kepada kelompok-kelompok "pemberontak" tersebut pertama-tama di pulau Pangkor, Malasyia Barat, dan terakhir di Sabah (Alchaidar, 1999: 135).

Perlawanan atas kesenjangan dan diskriminasi serta berlanjutnya pengalihan tanah serta pergeseran penguasa politik di Mindanao tidak cukup lagi melalui sistem datu yang berlaku. Para pemimpin terpelajar bergabung dalam suatu kesadaran perjuangan terhadap dominasi Barat dan penjajahan di hampir seluruh dunia dan khususnya di Asia Tenggara sejak berakhirnya perang dunia II. Baik Nur Misuari maupun Salamat Hasyim, keduanya menjadi aktivis dan pemimpin gerakan mahasiswa dikampusnya masing-masing untuk melakukan gerakan terhadap penjajahan dan pemerintahan yang dianggap tidak adil. Kasus Jabidah Massacre dan Ilaga memecut mereka untuk bersatu dan membangkitkan Muslim Mindanao dalam perlawanan terhadap pemerintah pusat dengan melihat kenyataan yang berlangsung di daerah asalnya, yaitu Mindanao.

Tragedi Jabidah telah mengorbankan masyarakat Muslim Moro di Corregidor dan mendorong tokoh politik Islam Filipina bernama Nur Misuari untuk bangkit memperjuangkan nasib Muslim Moro melalui organisasi. Pada tahun 1971, Nur Misuari, mencoba mencari penyelesaian lewat jalur konstitusional. Sebagai seorang intelektual muda yang ingin memajukan daerahnya, Misuari sebetulnya banyak diharapkan oleh masyarakat di Mindanao. Tetapi ia gagal bukan karena sabotase atau rintangan politik dari para politisi yang beragama Khatolik, tetapi tragisnya justru oleh para pemimpin Islam yang tidak mau kehilangan kedudukan di Kongres.

Misuari merasa kecewa dengan para pemimpin Islam, maka itu ia kembali ke kampung halamannya dan mengorganisasikan perlawanan bersenjata terahadap pemerintah pusat Filipina di Manila. Dia menyepakati pikiran dan cara perjuangan sekelompok intelektual muda Islam Filipina yang sedang belajar di Jeddah, Saudi Arabia. Para intelektual muda yang bertahun-tahun kecewa terhadap keadaan di Mindanao mula-mula membentuk sebuah kelompok diskusi. Kelompok ini kemudian meluas menjadi sebuah organisasi yang mempunyai sayap militer yang kuat yakni Moro National Liberation Front

Gerakan MNLF awalnya adalah sebuah secessionist movement (dan bukan gerakan separatis, seperti, banyak disebut media Barat). Sebagai sebuah gerakan pemisahan untuk kemerdekaan, MNLF banyak menggunakan idiom-idiom mitos Islami. Ketika para pemuda Muslim Filipina dilatih di Sabah, Malaysia, pada masa Perdana Menteri Sabah Tun Mustapha, mereka sering menamakan kelompok-kelompok perlawanan bersenjata mereka menurut "istilah-istilah mitos" seperti "Darul Islam" dan "NIM" di Cotabato, "Lamalip" di Lanao, " the Muslim Brotherhood" (istilah lain untuk al-ikhwan al-Muslimum) di Jolo, "Green Guards" di Zamboanga dan Basilan. 
Kebudayaan kolonial menurut MNLF adalah pencerminan dari peradaban Kristen diawali dari insiden-insiden yang terjadi pada tahun 1968 hingga lahirlah suatu kesadaran revolusioner dikalangan rakyar Muslim dan munculah Moro National Liberation Front. MNLF adalah organisasi nasional yang mencontoh gerakan anti kolonial dan didirikan secara sembunyi-sembunyi pada akhir tahun 1971. MNLF adalah organisasi perlawanan yang umum terbentuk di banyak bagian dunia ketiga, seperti FLN (The Nationalm Liberation Front) di Aljazair, PLO (Palestina United Liberation Organization) di antara orang Arab Palestina, atau PULO (Pattani United Liberation Organization) di antara orang Melayu di daerah Thailand Selatan. Akan tetapi, gerakangerakan Islam diatas seperti MNLF, FLN, PLO, PULO, dan lain sebagainya mempunyai tujuan yang utama adalah :

Pertama, mengembalikan rasa percaya diri kaum Muslimin. Kekalahankekalahan yang terjadi telah mewariskan kebimbangan, kelemahan, ketidakpercayaan terhadap diri dan agama pada mereka. Karena itu, para prisoner gerakan-gerakan Islam mengatakan, "Sesungguhnya, masalah pertama yang menjadi perhatian dakwah kami, dan hal yang penting yang kami fokuskan dalam kemunculan, perkembangan, dan penyebarannya adalah kebangkitan spiritual. Kami menginginkan jiwa-jiwa yang hidup, kuat perkasa, hati-hati yang segar dan bergelora, perasaan yang bergairah dan menyalanyala, semangat yang membara, pandangan jauh ke depan, idealisme yang tinggi, dan tujuan yang luhur, agar jiwa itu menghadap kearahnya, mendambakannya, dan kemudian sampai kepadanya.

Kedua, menyatukan kaum Muslimin berdasarkan pemahaman yang jelas terhadap Islam. Berilmu dulu sebelum beramal. Selama kaum Muslimin tidak bertemu dalam pemahaman yang sama, perjalanan mereka tidak akan pernah lurus dan orientasi mereka tidak akan pernah padu. Musuh-musuh Islam telah menyadari benar akan urgensi pemikiran ini. Karena itu, mereka berusaha keras memenuhi perpusatakaan Islam dengan pemikiran mereka, yang sebagian besarnya berisi berbagai syubhat dan penyimpangan.

Ketiga, membebaskan negeri-negeri Islam dari semua kekuasaan asing. Karena itu, gerakan Islam senantiasa terlibat perang kemerdekaan, seperti di Turki, Afrika Utara, Mesir, Sudan, Nigeria, Palestina, negara-negara Syria, Irak, Indonesia, Pakistan, India, dan negara-negara Islam lainya. Tidak diragukan lagi bahwa kaum Muslimin telah mengambil langkah-langkah yang positif dalam menuntut kemerdekaan, mengembalikan kebesaran dan kehormatan bagi negri mereka (Thahhan, 2000: 34-37).

Terlepas gerakan-gerakan Islam di atas yang memiliki tujuan utama yang dalam usaha mencapai tujuan tersebut. Berbeda dengan gerakan MNLF ini yang memiliki Tujuan mobilisasi dukungan masyarakat Moro umumnya; perekrutan, pelatihan, dan memperoleh dukungan internasional. MNLF jelas diselenggarakan sendiri dengan tujuan akhir dalam mencapai kemerdekaan politik Filipina. Pada periode awal, MNLF memiliki kombatan yang berjumlah lebih dari 10 ribu orang, yang kemudian secara 


\section{Firmanzah}

Dinamika Gerakan Pembebasan Muslim Moro di Filipina Selatan:

Studi Terhadap Moro National Liberation Front (1971-1996)

periodik mendapatkan pelatihan kemiliteran di libia. Nur Misuari merupakan tokoh Mindanao yang mendapatkan pelatihan militer gelombang pertama yang dikenal dengan “Top 90”. Salamat Hashim (yang kemudian mendirikan MILF-Moro Islamic Liberation Front) dan Muhammad Ibrahim Murrad, mendapatkan pelatihan militer pada gelombang kedua, yang dikenal "Gelombang 300" yang dilatih secara kemiliteran di Penang, Malasyia (Suwandono, tt: 4). Kemudian diikuti dengan "Gelombang 67" atau kelompok Bombardir, yang memiliki kemampuan teknis dalam artileri ringan dari Malaysia.

Kepemimpinan baru yang dipimpin oleh Nur Misuari menemukan momentumnya pada MNLF bagi Bangsamoro. Kebanggaan Bangsamoro muncul bersamaan dengan penggunaan Islam sebagai identitas dan simbol perlawan politik dan sekaligus melawan cap keterbelakangan dan barbar atau uncivilized (tak beradab) dalam tradisi dan politik Filipina. MNLF, misalnya mampu membangun pasukan bersenjata Bangsamoro Armed Force (BAF) sampai berjumlah 20.000 hingga 30.000 orang dan mampu membangun memobilisasi bukan hanya laki-laki tetapi juga perempuan.

Simbol bendera MNLF mewakili keharmonian Bangsamoro yaitu hati, pikiran, dan tubuh. Bintang melambangkan kebajikan Bangsamoro dari kejujuran, keadilan, kesetaraan, dan toleransi untuk perbedaan individu yang memandu keputusan para pemimpin dan rakyat Bangsamoro. Warna bintang dan bulan sabit bewarna emas kuning yang melambangkan kebijaksanaan, kearifan Bangsamoro sebagai sebuah perjuangan yang tanpa henti. Keris pedang melambangkan kekuatan Bangsamoro yang membela kemerdekaan dan kebebasan rakyat. Warna dari keris pedang berwarna putih dengan strip kuning dan pegangannya memiliki lima garis-garis hitam.

Keris pedang adalah pusat yang lebih rendah dan menunjuk ke kanan, yang berarti pedang akan selalu membuat keputusan loyalitas untuk kepentingan ibu pertiwi Bangsamoro. Di atas keris pedang adalah bulan sabit dan di atas bulan sabit adalah bintang. Latar belakang bendera MNLF berwarna merah, yang melambangkan aktivisme, ketegasan, kegigihan, berhemat, dan pengorbanan dalam mendorong maju perjuangan revolusioner untuk bertahan hidup, penentuan nasib, dan kemakmuran. Bendera MNLF tidak mewakili simbol dari setiap kelompok agama, geografis, atau etnis.

Menurut Misuari Ideologi MNLF yaitu nasionalisme yang dari ayat Al-Qur'an, sebagai akar ideologis dari bangsa Moro. Dalam bahasa Tausug, tiga akar MNLF digambarkan sebagai Bangsa (bangsa), Hulah (tanah air), dan Agama (agama, yaitu Islam), agar mencerminkan perjuangan yang prinsip-prinsipnya bersahabat satu nasionalis dan teritorial, meskipun agama telah jelas menjabat sebagai panggilan demo dan titik fokus perlawanan terhadap pemerintah pusat. Dalam konteks ideologisasi organisasi, MNLF mengidentifikasi diri dengan ideologisasi nasional-sekuler dibandingkan dengan ideologi Islam. Pilihan politik MNLF tidak bisa dipisahkan dari 
latar belakang Nur Misuari sebagai aktivis gerakan sosialisme Islam selama masih mahasiswa (Surwandono, 2013: 65).

Stuktur Gerakan MNLF ini, setelah mengalami konsolidasi pada tahun 1972, memiliki struktur politik yang paralel dengan struktur militer. Struktur politiknya terdiri dari sebuah komite sentral, komite-komite yang berjumlah seluruhnya 20 buah, sebuah biro politik, sebuah biro propaganda dan intelejen, dan komite-komite provinsial dan barrio. Sayap senjatanya dibentuk dalam Bangsa Moro Army (BMA) yang memiliki seorang panglima (field marshal) yang tidak langsung berada di bawah garis komando komite sentral. Di bawahnya ada Field Marshal di tingkat provinsial, komando zona di tingkat kotamadya. Dalam struktur organisasi MNLF mirip dengan struktur partai-partai komunis atau organisasi-organisasi di Negara sosialis.

Ketika mahasiswa Nur Misuari dikenal dekat dengan jose Mare Sison, pendiri Partai Komunis Filipina (Community Party of Philippines, CPP). Di dikenal dekat dengan orang-orang kiri (Marxis dan Maois). Malah Misuari adalah pendiri organisasi mahasiswa Pemuda Patriotik- Kabataang Makabayang- (KM) yang berorientasi Marxis. KM ini berorientasi dengan New People Army yang berorientasi Maois di dalamnya tidak bersimpati pada perjuangan kaum Muslim. Misuari kemudian mengubah orientasi politiknya dan membentuk MNLF sebagai organisasi bawah tanah dan sayap militer Bangsamoro dan dia diangkat menjadi ketua. Usaha Misuari ini awalnya berjalan tidak mulus karena Bangsamoro yang mayoritas Islam mencurigainya sebagai agen komunis. Setelah diibuktikan dirinya taat beragama, namanya segera melejit. Misuari dan istrinya, Desdemona Tan, pada periode setelah perang tahun 1972 tinggal di Timur Tengah hingga tahun 1988.

Otak dari gerakan MNLF ini adalah seorang pengacara, Macapanto Abbas Jr. Ia menyusun organisasi MNLF ini dan mengisinya dengan ideologi Islam. Asal usul kata MNLF dapat dianalisis bahwa kata "Moro" berati perlawanan terhadap penjajahan Spanyol yang tidak pernah menyerah. "Front Pembebasan Nasional" untuk mengintensifikasikan gerakan sebagai suatu usaha untuk membebaskan diri dari Negara Filipina dan membentuk negara sendiri. Arti kata "Nasional" karena sifat perjuangan mereka bukan hanya sekedar gerakan untuk meminta hak yang sama atau sekedar otonom.

Menurut Taufik Abdullah dan Sharon Siddique mengatakan bahwa: "Dalam periode kontemporer, kembangkitan Islam di Filipina memiliki dua interpretasi. Pandangan yang radikal dipegang oleh para anggota Moro National Liberation Front (MNLF) yang merupakan minoritas di kalangan penduduk Muslim. Pandangan yang moderat dipegang oleh warga Muslim yang ingin memprakarsai berbagai perubahan dalam masyarakat yang lebih luas. Kebangkitan Islam sering dikaitkan dengan suatu interpretasi yang militant. Manifesto MNLF, misalnya, menyerukan pentingnya menegakkan apa yang mereka sebut sebagai "Bangsa Moro" (Abdullah, 1988: 347). 


\section{Firmanzah}

Dinamika Gerakan Pembebasan Muslim Moro di Filipina Selatan:

Studi Terhadap Moro National Liberation Front (1971-1996)

\section{Respon Muslim Moro dan Negara-negara Islam terhadap Lahirnya Gerakan Pembebasan Moro National Liberation Front}

Setelah berdirinya MNLF, Presiden Ferdinand Marcos menanggapi gerakan MNLF dan berbagai perlawanan Muslim di Mindanao dianggap sebagai pemberontak dengan memberlakukan Martial Law atau keadaan darurat perang pada tahun 1972 dengan mengirim tentara besar-besaran ke Mindanao untuk menumpas pemberontakan dan gerakan tuntutan merdeka yang mulai membesar. Reasksi keras dari presiden juga mengundang dukungan massif dari Bangsa Moro untuk MNLF semakin kuat. Dukungan itu datang disamping dari masyarakat luas di Mindanao dan Sulu, juga kelompok-kelompok perlawanan yang sudah terbentuk sebelumnya seperti MIM (Muslim Independence Movement) serta gerakan mahasiswa Moro di Manila dan di luar negeri. Bahkan para pemimpin tradisional yang disebut datu juga mendukung inisiatif mahasiswa di bawah kepemimpinan Misuari ini. MNLF memilih untuk menarik perhatian internasional. Dunia Islam terpanggil untuk mencari jalan damai antara pemerintah dengan pemberontak melalui berbagai pendekatan.

Ketika undang-undang keadaan perang diumumkan, maka beberapa kombatan MNLF termasuk Nur Misuari terdampar di Manila. Tetapi mereka berupaya mencapai daerah selatan. Selama ada usaha untuk menyita persenjataan di pedalaman Sulu, pasukan-pasukan tentara kadang-kadang disergap atau dipaksa mundur. Dalam suatu peristiwa, lebih dari 1000 orang-orang yang diserang, yang mengakibatkan hilangnya sejumlah orang dan perbekalan. Laporan-laporan kemenangan tentara khususnya tidak muncul dalam surat-surat kabar, sedangkan laporan-laporan tentang meningkatnya pemberontakan-pemberontakan Islam dengan menggunakan senjata-senjata canggih diberitakan secara meluas. Karena sukses-sukses yang diperolehnya sejak semula, maka pengaruh MNLF di kalangan kelompok-kelompok bersenjata Islam meningkat dan paling tidak, diakui secara nominal.

Nur Misuari sebagai pemimpin MNLF yang kharismatik juga diterima masyarakat internasional sebagai representasi Bangsa Moro yang Muslim. Tuntutan merdeka makin kuat bergejolak akibat dari jabidah Massarce dan Ilaga yang menyiram semangat perlawanan. Maka banyak Bangsa Moro yang secara sukarela menjadi pasukan bersenjata MNLF atau Bangsamoro Armed Force (BAF) untuk melawan tentara pusat AFP (Armed Force of the Philippines) dan pasukan para militer tersebut. Bukan hanya laki-laki yang terjun menjadi sukarelawan perang melainkan juga perempuan terutama di bagian perbekalan, logistik dan dapur umum untuk pelayanan terhadap pasukan yang terjun berperang. MIM (Mindanao Independent Movement) juga ikut bergabung dan mendukung MNLF.

Betapa semangatnya perlawanan MNLF, tercemin dari jumlah pasukan bersenjata MNLF atau the Bangsamoro Army (BA), sayap militer MNLF yang memiliki sedikitnya 20 ribu sampai 30 ribu personel. Pada awal tahun 1973, secara resmi diperkirakan bahwa pasukan militer MNLF Tentara Bangsa Moro berjumlah dari 
15.000 orang dan dapat diharapkan mencapai dua kalinya jika para pemimpin tradisional diajak untuk mendukungnya. Di Mindanao dan Sulu, pasukan tentara sedikit-dikitnya berjumlah 10.000 orang yang didukung oleh 30.000 orang tentara sipil tambahan, yang sebagian besar merupakan kaum penetap.

MNLF diketuai oleh Nur Misuari mendapat dukungan dari Organization of the Islamic Confrence (OIC/OKI), Islamic Confrence of Foreign Ministers (ICFM) dan Presiden Libya Muammar Khaddafi (Libya memberikan dukungan diplomatik, dana, serta persenjataan kepada MNLF) (Bresna, tt: 130). Jaringan internasional MNLF cenderung dibangun oleh Nur Misuari melalui kedekatan pribadi dengan Muamar Kadafi, dari Kadafi inilah, Misuari akhirnya memiliki akses kepada OKI untuk melakukan intenasionalisasi konflik di Mindanao. Sehingga pada akhirnya MNLF menjadi wakil resmi masyarakat Mindanao.

Ada beberapa alasan tentang meningkatnya simpati di kalangan anggota konferensi Islam terhadap MNLF. Banyak pejabat Islam asing sangat dikecewakan oleh persaingan-persaingan dan perbedaan-perbedaan yang kronis para pemimpin Islam Tradisional yang terkemuka, dan banyak diantara pemimpin itu lebih memperhatikan soal-soal pribadi atau keluarga dari pada dalam masalah Islam. Sebaliknya, pemimpinpemimpin Islam MNLF tampil dengan pengabdian dan kemauan untuk menyingkirkan kepentingan-kepentingan pribadi untuk melindungi dan mempertahkan komunitas Islam.

Pemimpin-pemimpin Libya terkesan oleh idealisme MNLF dan ide-ide pembaharuan, khususnya dari Nur Misuari. Tetapi yang paling penting adalah bahwa MNLF telah mendemontrasikan dirinya menjadi kelompok bersenjata Islam yang secara militer diorganisasi dengan baik dan kuat. Dukungan Libya terhadap MNLF memang kukuh tak tergoyahkan dan semua anggota ICFM mungkin kini telah mendukung semua kehendak MNLF, yang secara esensial menghindarkan kemungkinan terjadinya kesukaran atau sakit hati Malasyia, sebagai tuan rumah yang telah berbuat sebaikbaiknhya untuk mengurangi perbedan-perbedaan dengan Filipina pada masa lalu.

\section{Konflik Bersenjata Gerakan Pembebasan Moro National Liberation Front dan Pemerintah}

Pada pertengahan bulan maret, sementara tentara sedang bertempur sengit melawan berbagai kelompok MNLF yang dipersenjatai dengan baik di Zamboanga, MNLF berhasil merebut kota madya-kota madya di Cotabato, dan mendudukinya untuk sementara waktu. Di tempat-tempat dimana kepolisian terutama telah bertindak kejam pada waktu yang lalu, serangan balik orang-orang Islam kini menjadi begitu gencar, sehingga banyak tentara yang dipenggal kepalanya. Serangan dalam sekala besar itu, memperlihatkan kemampuan MNLF dalam mengkoordinasi dan memperluas operasinya secara seksama, telah menimbulkan keprihatinan mendalam di bagianbagian tentara, karena serangan mereka tidak seperti serangan yang dilakukan oleh 


\section{Firmanzah}

Dinamika Gerakan Pembebasan Muslim Moro di Filipina Selatan:

Studi Terhadap Moro National Liberation Front (1971-1996)

tentara panglima-panglima perang Islam tradisional, oleh bandit-bandit, atau oleh kelompok-kelompok terisolir, terlokalisasi, dan kadang-kadang tidak diorganisasi. Pada saat sekarang ini pun, MNLF telah berhasil mendirikan propaganda di luar negeri di negara-negara Islam.

Pada tanggal 6 Februari 1974, terjadilah pertempuran berskala besar antara pasukan-pasukan pemerintah dan MNLF di Jolo, ibu kota Prov. Sulu. Pertempuran ini mengakibatkan kehancuran kota hampir menyeluruh. Kekuatan MNLF kemudian dapat menduduki dua kota besar, yang salah satunya Maimbung, dan pernah menjadi ibu kota daerah sultan-sultan Sulu. Pada malam hari 6 Februari 1974, hampir 100 orang pemberontak MNLF pos terdepan daerah itu. Tidak sampai keesokan sorenya, pasukanpasukan pemerintah dapat sepenuhnya dimobilisai untuk mengusir kaum pemberontak dan untuk mematahkan serangan mereka. Tank-tank dan pesawat perang dikerahkan untuk menaklukan kaum pemberontak. Sementara itu, tiga kapal patrol angkatan laut terus-menerus membom kota, sehingga mengakibatkan kehancuran berat. Pasukanpasukan MNLF dipaksa mundur ke pedalaman pulau.

Pemberlakuan UU darurat perang oleh presiden Marcos pada tahun 1972 telah menelan korban sedikitnya 100 ribu orang sipil dan tentara di kedua pihak. Keadaan darurat pada 1972 ini diberlakukan Marcos mengarah pada semakin memburuknya pelaksanaan hukum. Masyarakat baru yang ingin dibangun oleh Marcos merupakan upaya untuk memperbaiki kebobrokan yang melanda Filipina Sebagai negara. Kaum Muslim tentu saja terpengaruh, namun pada tingkat pemerintahan mereka telah diberi konsensi. Pemberontakan kaum Muslim dilihat sebagai sesuatu yang terlalu mahal dan tidak perlu (Thohir, 2012: 365). Sampai kemudian kekerasan dan perang itu mengundang keterlibatan pihak internasional terutama OKI (Organisasi Konferensi Islam) yang ketika itu diketuai oleh Libya di bawah presiden Moammar Qaddafy. OKI melalui Qaddafy cukup intens dalam memfasilitai upaya damai MNLF sebagai refrenstasi Bangsamoro dengan GRP (Government of the Republic of the Philippines) yang kemudian tercapai Peace Agreement (PA) Tripoli pada tahun 1976.

\section{Perjanjian Tripoli Agreement 1976 Langkah Pertama Menuju Perdamaian}

MNLF secara langsung sudah terlibat dalam perlawanan pasukan anti llaga Kristen. MNLF baru muncul secara resmi ketika kekerasan kolonial menjadi meluas setelah Presiden Marcos mengumumkan perang November 1972. MNLF dengan sengaja tetap berada di belakang layar. Sementara itu masyarakat Muslim Moro melakukan perlawanan masing-masing terhadap teror-teror kolonial. Serangkaian perjanjian kemudian dilakukan antara pemerintah Filipina dengan perwakilan Mindanao yang diwakili oleh MNLF dengan mediator dari OKI dan negara-negara Muslim seperti Libia, Indonesia, Malasyia, Arab Saudi, dan Jordania. Dengan bantuan pengawasan OKI lahirlah sebuah "Perjanjian Tripoli" (Tripoli Agreement) (Dardiri, 2006: 128). Perjanjian Tripoli dilaksanakan Pada tanggal 23 Desember 1976, yang menetapkan 
prinsip-prinsip umum bagi otonomi Islam di Filipina Selatan (Lihat lengkap naskah perjanjian Tripoli Lampiran II).

Dalam PA Tripoli ini, delegasi MNLF langsung dipimpin oleh DR. Nur Misuari, dari pemerintah Filipina diwakili oleh Zamello Z. Barbero. Delegasi dari kelompok quadripartite di wakili oleh; Dr Ali Abdussalam Treki (Menlu Libia), H.E. salah Abdalla el-Fadl (Duta Besar Arab Saudi untuk Libia), Abu Bakar Othman (perwakilan Senegal di Kairo), Dr. Amadou Karim Gaye, Sekjen OKI, dan delegasi dari secretariat OKI yang terdiri dari Mr. Qasim Zuheri, Assistan Secretary General, dan Mr. Aref Ben Musa, Director of Political Department. Konferensi Tripoli diselenggarakan untuk menyelesaiakan masalah Muslim Filipina.

Peace Agreement Tripoli 1976 disebutkan wilayah-wilayah yang akan menjadi bagian dari otonomi Bangsamoro, yaitu 13 Provinsi dan Sembilan pemerintahan setingkat kota dari 25 Provinsi Pulau Mindanao dan kepulauan yang ada ketika itu. Disamping itu, juga dilakukan akomodasi terhadap sejumlah kombatan MNLF dari Bangsamoro Army dan relawan MNLF ke dalam kesatuan AFP (Armed Force of the Philippines) dan kepolisian Filipina. Dalam proses pembicaraan hingga tercapainya PA Tripoli tersebut, MNLF telah mengubah tuntutan dari merdeka atau memisahkan diri ke tuntuan otonomi di bawah negara kesatuan RP (Republic of the Philippines).

Pada intinya Tripoli Agreement 1976 menghasilkan dua hal pokok; pertama, pembentukan pemerintah otonomi di wilayah Filipina Selatan dalan lingkungan kedaulatan dan teritorial Filipina. Kedua, wilayah otonomi Muslim di Filipina Selatan meliputi: Basilan, Sulu, Tawi-Tawi, Zamboanga del Sur, Sultan Kudarat, Lanao del Norte, Lanao del Sur, Davao del Sur, South Cotabato, Palawan. Semua kota dan desa yang berada di wilayah tersebut. Ketika persetujuan disempurnakan, pihak pemerintah Filipina berusaha menghindar dari apa yang telah disepakati dan meningkatkan kegiatan sabotase terhadap pasukan Muslim. Hasilnya cukup mengecewakan MNLF karena dari 13 wilayah tersebut hanya empat yang bersedia bergabung.

MNLF tidak sejalan dengan semangat Tripoli Agreement di mana 13 wilayah yang masuk dalam kesatuan otonomi secara eksklusif langsung masuk di pemerintahan otonomi Mindanao. Jika melihat setelah penandatanganan Perjanjian Tripoli, tampak jelas bahwa Marcos menginginkan negosiasi hanya agar dirinya bisa meyusun kekuatan lagi untuk menundukkan pejuang Muslim Moro. Pemerintah Filipina kemudian terangterangan menolak melaksanakan amanat perjanjian Tripoli. Marcos tidak peduli dengan perjanjian Tripoli atau perjanjian-perjanjian internasional. Konsekuensinya adalah terjadinya "drama" pemberontakan yang dilakukan oleh kaum Muslim Filipina terhadap pemerintah hingga akhir tahun 1977.

Implementasi (pelaksanaan) dari perjanjian Tripoli ini diwarnai berbagai aksi penyabotan yang dilakukan pemerintah Filipina yang saat itu dipimpin oleh marcos. Mereka melancarkan kampanye "cari dan hancurkan" MNLF. Akibatnya, terjadi banyak 


\section{Firmanzah}

Dinamika Gerakan Pembebasan Muslim Moro di Filipina Selatan:

Studi Terhadap Moro National Liberation Front (1971-1996)

kontak senjata dan kekerasan kembali terjadi diwilayah Filipina Islam tersebut. Korban yang jatuh selama konflik berlangsung tidak kurang dari 15.000 orang, sebagian di antaranya adalah perempuan dan anak-anak. Hal itu dikutuk habis-habisan oleh Nur Misuari, yang pada saat itu menjabat sebagai ketua Komite Sentral MNLF, ketika ia menyampaikan pidato di hadapan kongres Internasional mengenai impreialisme kebudayaan di Palais des Nations, Aljir, Aljazair, pada oktober 1977 (Lihat lampiran VI tentang pidato Nur Misuari terkait dengan Pemusnahan Kebudayaan Islam) (Abdullah, $\mathrm{tt}:$ 480).

Nur Misuari kecewa dengan pemerintahan Marcos yang tidak merealisasikan untuk melakukan pengakuan kepada hak khusus pemerintahan otonom Mindanao untuk mendirikan pengadilan syari'ah, sekolah, sistem adminitrasi, sistem ekonomi, dan keuangan, keamanan kawasan (Special Regional Security Force), badan perwakilan dan dewan eksekutif, integrasi kombatan MNLF ke dalam Armed Forces of the Phillipines, dan kepolisian keterwakilan daerah otonom pemerintah pusat, serta persentase yang proposional berkaitan dengan pendapatan dari sektor pertambangan dan mineral sebagai pendapatan untuk daerah otonom.

\section{Perjanjian Final Peace Agreement 1996 Langkah Akhir Menuju Perdamaian}

Perjanjian Tripoli Agreement 1976 memang menjadi awal dari perjalanan dinamika gerakan MNLF ini, Ketika ketidakpuasan sedang berlangsung baik ditunjukkan dari makin kuatnya MILF maupun ketidakpuasan MNLF terhadap kebijakan marcos, maka terjadi penggantian kepemimpinan nasional dari Marcos ke Corazon Aquino. Pergantian ini agaknya lebih diharapkan oleh golongan Islam untuk memperhatikan kepentingan otonomi mereka. Perjuangan Muslim Moro di Filipina Selatan memasuki babak baru (Musbikin, 2013: 215). Rezim Aquino yang menggantikan rezim Marcos di 1992 cenderung mengembangkan kebijakan akomodatif terhadap kelompok perlawanan Mindanao dari pada kebijakan refresif. Pilihan kebijakan ini tidak bisa dilepaskan dari spectrum politik di Filipina dan dukungan internasional untuk menyelesaikan konflik Mindanao di meja perundingan.

Aquino melakukan langkah-langkah dalam menyelesaiakan konflik di Filipina Selatan, dengan melakukan pertemuan informal dan formal dengan elite-elite MNLF dan beberapa negara Timur Tengah sebagai fasilator negosiasi. Dalam menghadapi mobilasi kekuatan bersenjata Moro di Mindanao, Corazon Aquino memilih pendekatan baru kepada Moro sebagai bagian dari kampanye rekonsiliasi nasionalnya. Presiden Aquino mengirim iparnya, Agapito Aquino ke Jeddah untuk berdialog dengan Nur Misuari agar bersedia kembali melakukan negosiasi dengan pemerintah Aquino dengan pemberian konsesi politik otonomi Moro di Mindanao yang lebih luas.

Aquino sebagai presiden menunjukkan niat baik, beberapa bulan setelah dilantik menjadi presiden menemui Nur Misuari di kota Jolo, ibu kota Provinsi Sulu, yang merupakan basis markas MNLF. Kedatangan Aquino ke Jolo adalah untuk melanjutkan 
pembicaraan damai langsung dengan Misuari yang sempat terhenti di masa Marcos, meskipun sesungguhnya kedatangan itu dicegah oleh Menteri Pertahanan ketika itu karena dianggap membahayakan dirinya. Aquino berhasil mengajak Misuari kembali ke meja perundingan. Aquino membangun formula dengan menerjemahkan PA ke dalam bentuk Undang-undang, yaitu Undang-undang Organic Arc on Autonomy for Muslim Mindanao (ARMM) yang kemudian dimasukkan kedalam perubahan Konstitusi 1987 dengan nama ARMM (Autonomos Region in Muslim Mindanao).

MNLF menolak persyaratan oleh Aquino karena dianggap menyimpang dari PA Tripoli, sementara pemerintah melaksanakan plebisit. Dalam pelaksanaan plebisit yang dipaksakan 19 November 1989, MNLF di bawah kepemimpinan Nur Misuari dan juga MILF menyerukan untuk memboikot. Hasilnya bisa di duga sangat mengecewakan dengan hanya empat Provinsi Yaitu Tawi-tawi, Sulu, Maguindanao, dan Lanao de Sure, yang menyatakan bergabung ke dalam ARMM dari 13 yang dituntut MNLF dan tidak satupun dari sembilan kota yang berada di dalam cakupan Provinsi tersebut. Bahkan kota Marawi yang merupakan ibu kota Provinsi Lanao de Sure, Cotabato ibu kota Maguindanao, dan juga Basilan, kepulauan yang besar ketika masuk bagian Sulu dan kini menjadi Provinsi kekacauan karena Provinsi yang bergabung dengan ARMM, sedangkan kota yang menjadi ibu kota provins-provinsi tersebut tidak bergabung.

MNLF menganggap bahwa pelaksanaan perjanjian tersebut tidak fair sehingga berakibat disamping mengundang kemarahan sebagian sayap MNLF juga mengundang makin tingginya perlawanan MILF. Maka dari itu, Ketegangan dan kekerasan pun kembali meningkat. Presiden Fidel V. Ramos yang naik menggantikan Aquino pada 1993 mencoba kembali merintis pembicaraan dengan MNLF dengan menjanjikan mengembalikan wilayah yang ada di dalam PA Tripoli dengan memasukan klausul terpenting pada Final Peace Agreement yang ditandatangi di Jakarata pada 2 September 1996, yaitu "the Final peace agrrement constitutes the full implementasi of the Tripoli Agreement".

Rancangan negosiasi ini dipersiapkan secara cermat baik oleh pemerintah Filipina dan negara-negara Muslim seperti Indonesia. Dan Libia yang difasilitasi oleh Organisasi Konferensi Islam. OKI juga menyiapkan fasilitasi yang lebih komprehensif agar kegagalan implementasi Tripoli Agreement 1976 tidak terulang lagi. Memandang pertikaian yang telah berlangsung setidaknya 2 dasawarsa ini, pemerintah Indonesia lewat Menlu Ali Alatas juga berperan besar mediator guna tercapainya perdamaian antara pihak-pihak yang bertikai. Di bawah payung OKI, Indonesia menjadi ketua dari enam negara anggota. Indonesia menawarkan berbagai fasilitas perundingan mulai dari Bogor, Jakarta, hingga Manila. Pada 1994, Indonesia meminta negara-negara OKI untuk menjadi pengamat perdamaian.

Setelah melalui beberapa tahap persiapan perjanjian, baik yang dilakukan pada era Corazon Aquino yang melahirkan Jeddah Accord, 3 januari 1987, yang menghasilkan pemerintahan otonomi Mindanao (Autonomous Region For Moro). 


\section{Firmanzah}

Dinamika Gerakan Pembebasan Muslim Moro di Filipina Selatan:

Studi Terhadap Moro National Liberation Front (1971-1996)

ARMM berhak mengelola wilayah otonomi secara penuh kepada lima provinsi besar yakni, Basilan, Tawi-Tawi, Maguindanao, Palawan, maka jalan perdamaian kembali terbuka. Pertemuan yang juga berperan bagi persiapan Final Peace Agreement adalah pertemuan ke-20 ICFM di Istambul dan Summit Meeting Organisasi Konferensi Islam, Desember 1991 di Senegal yang meminta pemerintah Filipina dan MNLF untuk melanjutkan perjanjian damai. Dalam pertemuan ini, usulan Nur Misuari kembali mengusulkan pemisahan diri ditolak forum, sebab dalam banyak hal pemerintah Filipina pasca rezim Marcos jatuh lebih menunjukkan apresiasi terhadap masalah Mindanao.

Final Peace Agreement mulai menunjukkan kemajuan yang signifikan pasca pertemuan Nur Misuari dan Ramos di Jakarta, April 1993 dan Desember 1995. Muaamar Khadafi dan Soeharto tersebut sangat berperan untuk mengajak Misuari agar tetap menggunakan jalan damai dalam memperjuangkan masyarakat Midanano. Sebagai fasilitator, Organisasi Konferensi Islam sangat optimis bahwa proses penyelesaian konflik Mindanao melalui negosiasi akan berhasil baik. Pada tanggal 16 Agustus 1996, wakil-wakil dari MNLF dan pemerintah Filipina sepakat bertemu guna merundingkan rencana perdamaian di Istana Merdeka, Jakarta. Selanjutnya pada tanggal 2 September 1996, naskah perjanjian perdamaian ditandatangani oleh Nur Misuari (ketua MNLF) dan Fidel Ramos (presiden Filipina) di Manila. Penandatangan itu dilakukan Ketua Juru Runding Pemerintah Filipina; Manuel T Yan, dan ketua MNLF Nur Misuari.

Pada 2 Desember 1996, Final Peace Agreement sebagai hasil negosiasi panjang semenjak tahun 1992, berhasil disepakati oleh kedua belah pihak yang berkonflik, dengan ditandatanganinya dokumen hasil negosiasi oleh Nur Misuari yang mewakili MNLF dan Fidel Ramos yang mewakili pemerintah Filipina. Proses penandatanganan Final Peace Agreement1996, dengan disaksikan oleh menteri luar negeri Indonesia Ali Alatas dan Seketaris Jenderal OKI, Hamid Algabid. Kesuksesan negosiasi babak baru yang di fasilitasi oleh Indonesia ini, menghasilkan sebuah kesepakatan sementara yang mencakup 81 poin consensus.

Final Peace Agreement membentuk sebuah institusi transisi bernama SZOPAD (Special Zone for Peace and Development) yang meliputi wilayah yang diklaim MNLF dalam PA Tripoli tersebut. Selain itu, dibentuk dua institusi untuk memfasilitasi penguatan terhadap SZOPAD, yaitu SPCPD (Southern Philppines Councel for Peace and Development) dan Consultative Assembly (CA) bertugas selama tiga tahun untuk memperkuat wilayah-wilayah tersebut untuk kemudian memiliki otonomi kemandirian politik regional dengan kekuasaan yang lebih besar dan cakupan wilayah lebih besar dan cakupan dari yang ada di dalam eksistensi cakupan ARMM ketika itu.

ARMM meliputi wilayah berlokasi di kepulauan Mindanao teritori Republik Filipina, terdiri dari provinsi penduduk dominan muslim, yaitu Basilan (kecuali Isabela City), Lanao del Sur, Maguindanao, Sulu dan Tawi-Tawi yang meliputi wilayah seluas 12,288 Km2, dengan total penduduk 3,326.140 jiwa. ARMM diinaugerasi pada 6 November 1990 di Cotabato ibukota ARMM. Ada sejumlah program yang dilakukan 
bagi implementasi ARMM ini, terutama yang didanai oleh organisasi internasional, seperti World Bank. Program ini diorientasikan untuk pengurangan angka kemiskinan, keterbelakangan, dan penguatan politik Mindanao. Misalnya, ARMM Social Fund Project (ASFP) yang diantaranya bertujuan; 1) untuk meningkatkan kemampuan akses (bagi orang miskin dan dampak konflik) terhadap layanan ekonomi dan sosial; 2) meningkatkan kapasitas ekonomi, peroleh pekerjaan, dan pendapatan rumah tangga bagi perempuan dan siswa putus sekolah; 3) meningkatkan kohesi sosial dan kemitraan antara masyarakat yang tergabung dalam ARMM serta; dan 4) peningkatan potensi lokal. Untuk peningkatan kualitas pendidikan dan pengurangan angka buta huruf di Muslim Mindanao, Aus Aid mendanai program Basic Education Assistance for Mindanao bagi ARMM (BEAM-ARMM) (Yusuf, tt: 80-82).

Sembilan hari pasca penandatanganan FPA, pemerintah Filipina mengadakan pemilihan umum untuk menentukan siapa yang akan menjadi Gubernur wilayah otonomi Mindanao. Dalam pemilihan ini, Nur Misuari terpilih sebagai Gubernur Mindanao dengan jumlah perolehan suara yaitu $90 \%$ dari jumlah pemilih yang ada setelah mendapatkan dukungan dari LAKAS Party. Segera setelah itu, Ramos mengumumkan untuk membentuk badan eksekutif perdamaian di Mindanao yang kemudian disebut The Southern Philippine Council for Peace and Development (SPCPD), yang akhirnya juga diketuai oleh Nur Misuari.

Dua posisi politik strategis ini memang menjadi prasyarat yang diajukan Bangsa Moro dalam mewujudkan perdamaian dengan pemerintah Filipina. Duduknya Nur Misuari sebagai Gubernur ARMM dan ketua SPCPD, sebagai jaminan Bangsa Moro diberi otonomi seperti yang kami tuntut dalam perang lebih dari 20 tahun terakhir." Ungkap Sekjen MNLF," Muslimin Sema. Bagi Misuari sendiri, penandatangan perjanjian perdamaian ini merupakan prgamatis dan realistis. "Kami Bangsa Moro tidak pernah menginginkan perang. Karena perang justru merupakan pilihan terakhir yang terpaksa harus kami lakukan. Saya tegaskan bahwa kami ingin damai," ungkap Ketua MNLF yang terlahir dengan nama Nurulhaji Misuari. Langkah-langkah awal yang akan ditempuh Misuari adalah memperbaiki ekonomi warganya, untuk mengejar ketertinggalan dengan masyarakat Filipina di bagian Utara. "Bahkan kami optimis, Mindanao akan menjadi pusat ekonomi dan perdagangan di Asia, seperti pada zaman keemasan kesultanan Sulu," tandas Misuari berbinar-binar.

\section{Kesimpulan}

Dinamika gerakan pembebasan MNLF sendiri dimulai dari berdirinya yang dianggap pemerintah sebagai pemberontak sangat sulit untuk berkembang, akan tetapi karena perjuangan jihad yang dilakukan MNLF sendiri sehingga membuka mata dunia bahwa MNLF berideolisme Islam dan sangat butuh bantuan dari Negara-negara Islam, ini terbukti organisasi konferensi Islam yang berpusat di Libya memberikan dukungan baik materi maupun material. Sedangkan untuk Negara-negara Islam MNLF mendapat bantuan dari Malasyia, Indonesia, Libya dan lain-lain. MNLF yang diketuai oleh Nur 


\section{Firmanzah}

Dinamika Gerakan Pembebasan Muslim Moro di Filipina Selatan:

Studi Terhadap Moro National Liberation Front (1971-1996)

Misuari dan sebagai Hasim Salama tmau menandatangani perundingan pertama pada tahun 1976, atau lebih dikenalnya dengan Perjanjian Tripoli 1976 yang diselenggarakan di Libya tepatnya kota Tripoli. Di dalam perjanjian di sepakati 13 wilayah masuk kedalam otonomi Filipina Selatan.

Dinamika gerakan pembebasan MNLF selanjutnya terjadi pasca penandatangan Perjanjian Tripoli 1976, dimana wakil dari MNLF yaitu Hasim Salamat keluar dari MNLF dan mendirikan MILF (Moro National Liberation Front), selanjutnya anggota MNLF yaitu Abdul Rajak mendirikan Abu Syyaf Group yang cara gerakannya melakukan penyanderaan. Pada tahun 1996 terjadilah sebuah perdamaian antara pemerintah dan MNLF yang dilaksanakan di Indonesia tepatnya di Istana Merdeka, Jakarta. Perjanjian ini dikenal dengan Final Peace Agreement 1996 dimana ini sebuah penantian panjang MNLF yang akhirnya menghasilkan ARMM (Autonomy Regional Mulsim Mindanao) dan Nur Misuari terpilih menjadi Gubernur dan ketua SZOPAD (Southern Philippines Caouncel for Peace and Development). 


\section{Daftar Pustaka}

Abdullah, Taufik dkk. 1988. Ensiklopedia Tematis Dunia Islam Asia Tenggara. Jakarta: Itchiar Baru Van Hoeve.

Apipudin. 2008. Islam Asia Tenggara. Jakarta: Akbar Media EkaSarana.

Hidayat, Asep Ahmad dkk. 2014. Studi Islam di Asia Tenggara. Bandung: Pustaka Setia.

Yusuf, Choirul Fuad dkk. 2013. Dinamika Islam Filipina, Burma, dan Thailand. Jakarta: Puslitbang Lektur dan Khazanah Keagamaan Badan Litbang dan Diklat Kementrian Agama RI.

Alchaidar. 1999. Wacana Ideologi Negara Islam Studi Harakah Darul Islam dan Moro National Liberation Front. Jakarta: Darul Falah.

Dardiri, dkk. 2006. Sejarah Islam Asia Tenggara. Riau: Institute for Southeast Asean Islamic Studies.

K, A. Sukandia. 1999. Politik Kekerasan. Bandung: Mizan.

Kettani, M. Ali. 2005. Minoritas Muslim di Dunia Dewasa Ini. Jakarta: Raja Grafindo Persada.

Musbikin, Imam. 2013. Studi Islam Kawasan Pengumulan Islam Dengan Budaya Lokal. Pekan Baru Riau: Zanafa Publishing.

Suaedy, Ahmad. 2012. Dinamika Minoritas Muslim Mencari Jalan Damai Peran Civil Society Muslim di Thailand Selatan dan Filipina Selatan. Jakarta: Puslitbang Lektur dan Khazanah Keagamaan Badan Litbang dan Diklat Kementrian Agama RI.

Saifullah. 2010. Sejarah dan Kebudayaan Islam di Asia Tenggara. Yogyakarta: Pustaka Pelajar.

Seagrave, Sterling. 1996. Dinasti Marcos Korupsi Dan Kekuasaan Di Filipina. Jakarta: Dunia Pustaka Jaya.

Surwandono. 2013. Manajemen Konflik Separatisme Dinamika Negosiasi dalam Penyelesaian Konflik Mindanao.Yogyakarta: Pustaka Pelajar.

Thahhan, Muhammad Musthafa. 2000. Rekonstruksi Pemikiran Menuju Gerakan Islam Modern. Solo: Era Intermedia.

Yahya, Mahayudin. 1993. Sejarah Islam. Shah Alam: Fajar Bakti Sdn Bhd.

Ibrahim, Qasim A, dan Muhammad A Saleh. 2014. Sejarah Islam. Jakarta: Zaman. 


\section{Firmanzah}

Dinamika Gerakan Pembebasan Muslim Moro di Filipina Selatan:

Studi Terhadap Moro National Liberation Front (1971-1996)

Intelektualita: Volume 06, Nomor 01, 2017 